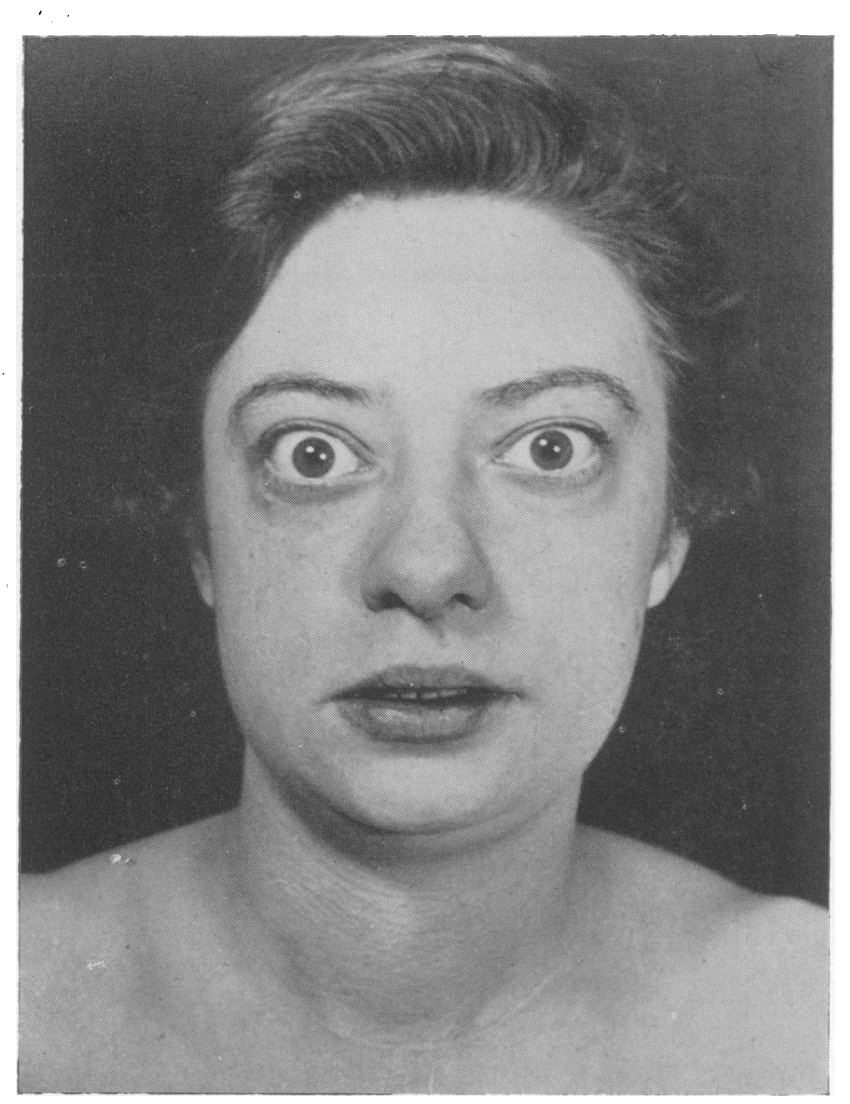

FIG. I.-Primary thyrotoxicosis: Grave's disease (exophthalmic goitre). Treated with thiouracil but relapsed. Stabilized following sub-total thyroidectomy.

\section{Toxic Goitre}

It is convenient to retain the terms primary toxic goitre and secondary toxic goitre or toxic nodular goitre, although the one merges imperceptibly into the other, if for no other reason than that the extreme examples of these two varieties (Figs. I and 2) usually require different management. Secondary toxic goitre is better ${ }_{\sigma}^{\omega}$ called toxic nodular goitre because it is the nodular element when this is marked, rather than the toxic? element, which differentiates this group from the primary toxic goitres and is responsible for the special treatment (usually surgical) which they mayo require. In toxic goitre the particular clinical 


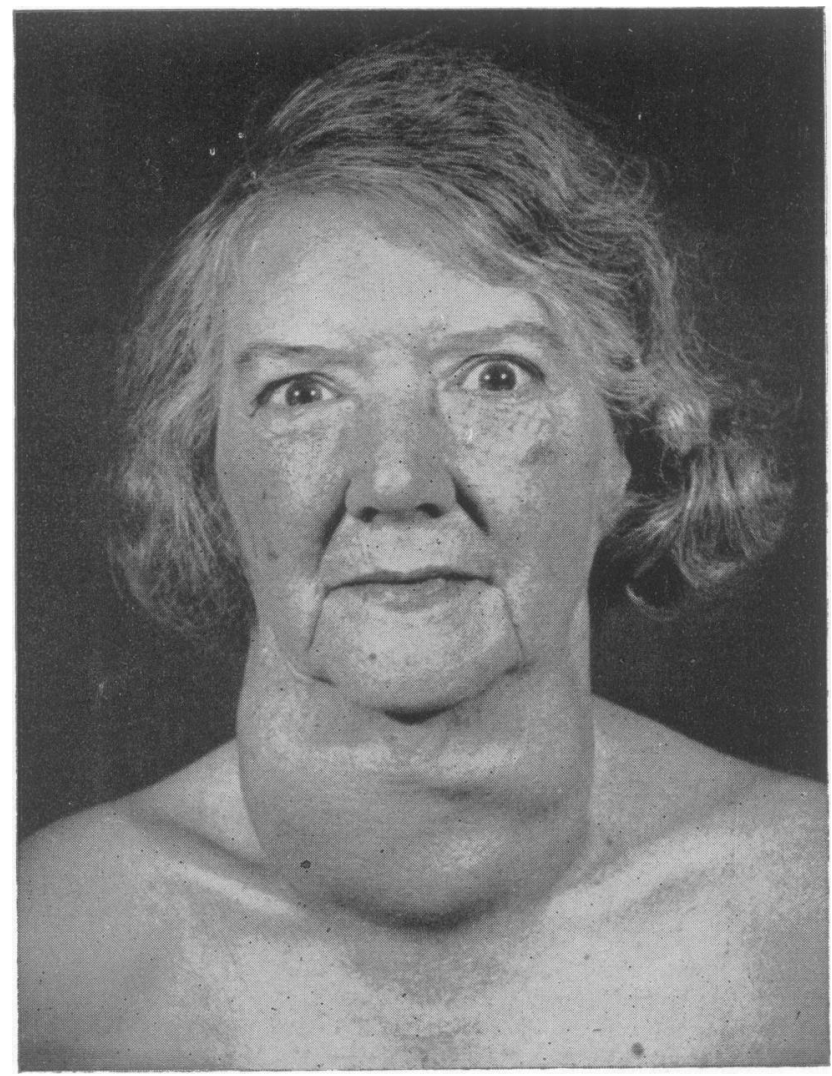

picture produced is the result of the interplay of two factors - the thyroid gland on the one hand and the tissues on the other. The gland can react totally if normal or only partially if nodular to the provoking stimuli. The tissues can resist the resulting toxaemia vigorously or feebly. Age is the catalyst in the reaction. The most unfavourable circumstances will be achieved when the gland reacts maximally and the tissues resist minimally. Fortunately the conditions most likely to produce this state of affairs do not commonly go together, for they imply a young gland and old tissues.

The Presenting Symptom. If the presenting symptom is associated with goitre or exophthalmos, the diagnosis is straightforward, but it is not impossible to miss a case of hyperthyroidism if there is no goitre and there are no eye changes-so-called masked hyperthyroidism, e.g. one patient may complain only of loss of weight, another only of swelling of the ankles and another only of sterility or amenorrhoea.

\section{Anti-Thyroid Agents}

The whole trend of therapy in thyrotoxicosis has been transformed in recent years by the discovery and introduction of the anti-thyroid substances. They have ushered in a new era of safety in thyroid surgery and they have rendered obsolete in all but the most exceptional cases the need for individual ligation of arteries and multiple stage operations.

By their agency a small group of patients with thyrotoxicosis can be cured or at least controlled without resort to surgery. For the remainder, surgery following upon a course of one of the antithyroid agents may be necessary, but by enabling us for the first time to fulfil our main pre-operative objective-the conversion of a toxic into a nontoxic goitre-they have removed much of the hazard and increased the accuracy of the operation.

When we speak today of the surgical treatment of thyrotoxicosis we infer treatment by combined medicine and surgery. Surgery is only the culminating act in the final phase of a combined method. In comparing the merits of the purely medical and the combined procedures it is important to bear in mind the altered circumstances in which thyroid surgery is conducted today. The 


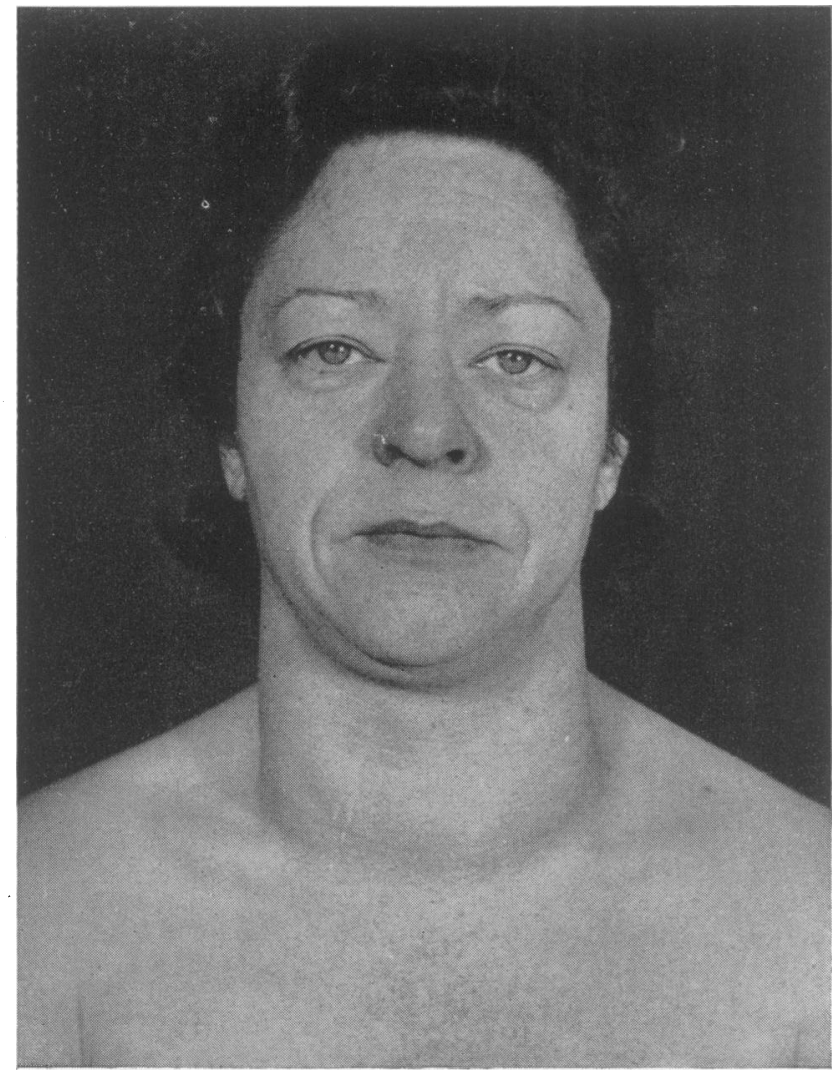

adverse conditions which existed prior to I943, when surgery so often had to be undertaken under the unfavourable conditions of uncontrolled toxicity, no longer exist, as a direct result of the introduction of the anti-thyroid substances.

This event has had its effect upon both patient and surgeon. It is now in our power to make the patient safe for surgery to a degree unknown prior to the thiouracil era. It is also in our power to make surgery safer for the patient, since there is no longer the same necessity for speed in operating as there was in the constitutionally ill and toxic subject. One great advantage which an unhurried operation affords is that it allows time for the deliberate identification of the parathyroid glands and recurrent laryngeal nerves so that the incidence of damage to these important structures has fallen. Equally important, a more accurate assessment of the amount of gland to be resected can be madea key decision in the operation, for nothing brings thyroidectomy for toxic goitre into such disrepute as inadequate procedures.

While the present satisfactory position is in part due to modern anaesthetic agents and methods it is in greater measure due to the thiouracils. It is incumbent therefore upon all surgeons using the antithyroid drugs for the pre-operative stabilization of their patients to be familiar with their potentialities. In addition it is essential to see the patients with their physician in their original thyrotoxic state before therapy is initiated. If seen $\sigma$ for the first time when a thiouracil effect has been $N$ obtained, an entirely false assessment of the N severity of the disease may be made and a wrong decision come to as to the need or time for surgical intervention.

\section{The Thiouracils}

Action. The anti-thyroid agents most commonly employed are methyl and propyl thiouracil. 

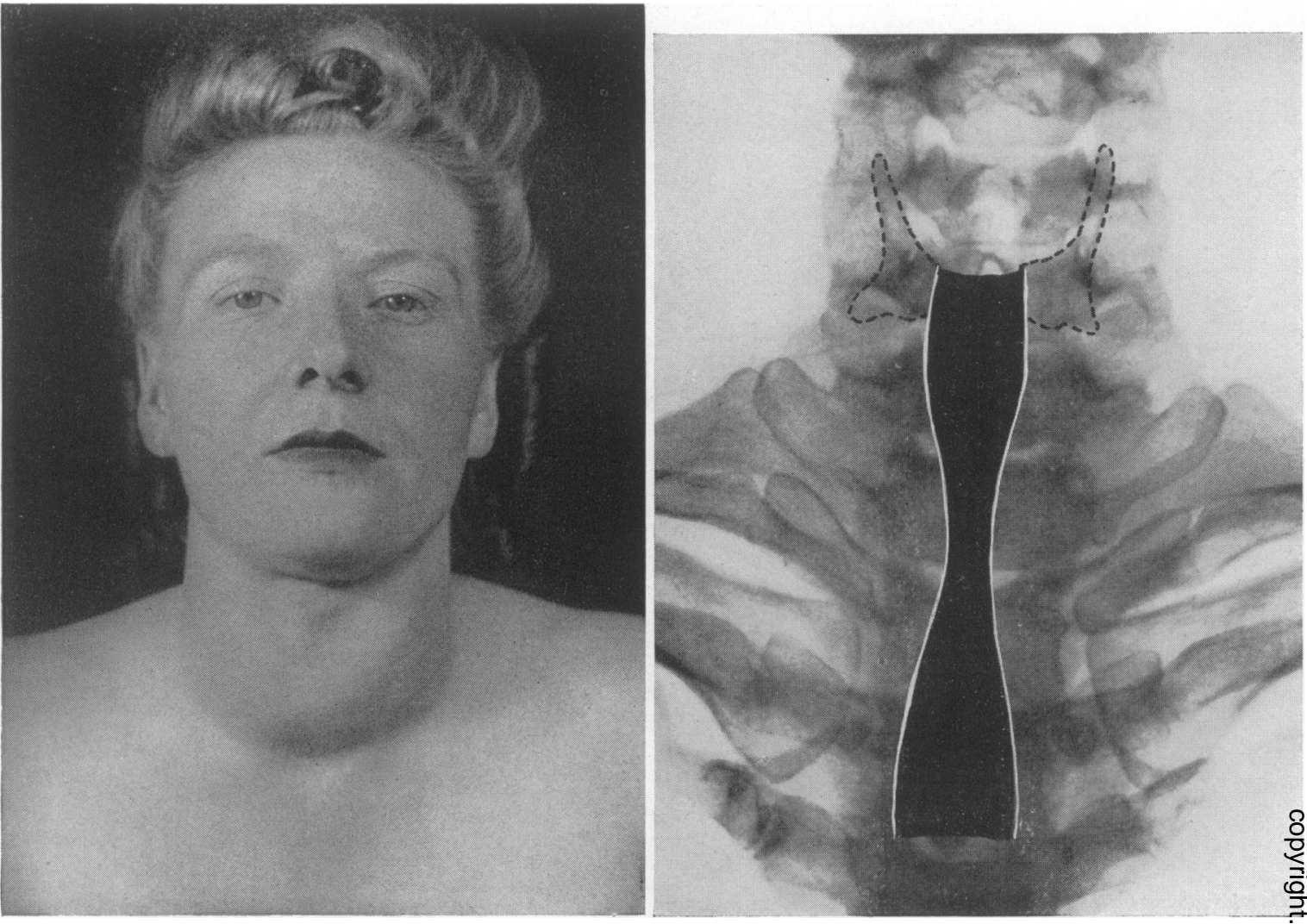

Fig. 4.-Compression of the trachea produced by thiouracil.

Their mode of action is to interfere with the synthesis of thyroxin within the thyroid gland by preventing the union of iodine and tyrosine into diiodotyrosine, which is the precursor of thyroxin. The resultant fall in the production of circulating thyroxin stimulates the anterior pituitary to an increased production of thyrotropic hormone and this in turn is followed by an ineffectual hyperplasia of the thyroid gland, clinically manifested in a proportion of patients by an increase in its size. The thiouracils do not effect the thyroxin already stored in the gland or in circulation, which explains the short time lag before clinical improvement is noticed following the initial administration of thiouracil.

\section{Leukopenic Reactions}

\section{Dangers}

Thiouracil is a poison to some individuals (owing to the high concentrations in which it may be stored in the bone marrow) and although the mortality from agranulocytosis is extraordinarily low considering the widespread use of the anti-thyroid agents, the fact remains that any therapeutic measure that carries with it the risk of death, however remote, requires that special precautions shall be taken in its application. It cannot be too strongly urged that routine blood counts as a safety method of control are not only useless but dangerous as the drug may strike with dramatic suddenness. Blood counts which may be normal one day may be seriously leucopenic the next. Fortunately this sudden and dramatic fall rarely, if ever, occurs without giving rise to warning symptoms. It is for this reason that the clinical method of control is recommended. For the clinical method of control to be safe, everyone coming in contact with the drug - patient, nurse and doctormust be absolutely familiar with its side effects, and immediate action taken upon any of the well known toxic features presenting (fever, malaise, nausea, headache, sore throat, rash, etc.). This action will take the form of instantly stopping the administration of the drug, of giving a prophylactic injection of penicillin and making an immediate examination of a blood smear. In the latter con- 

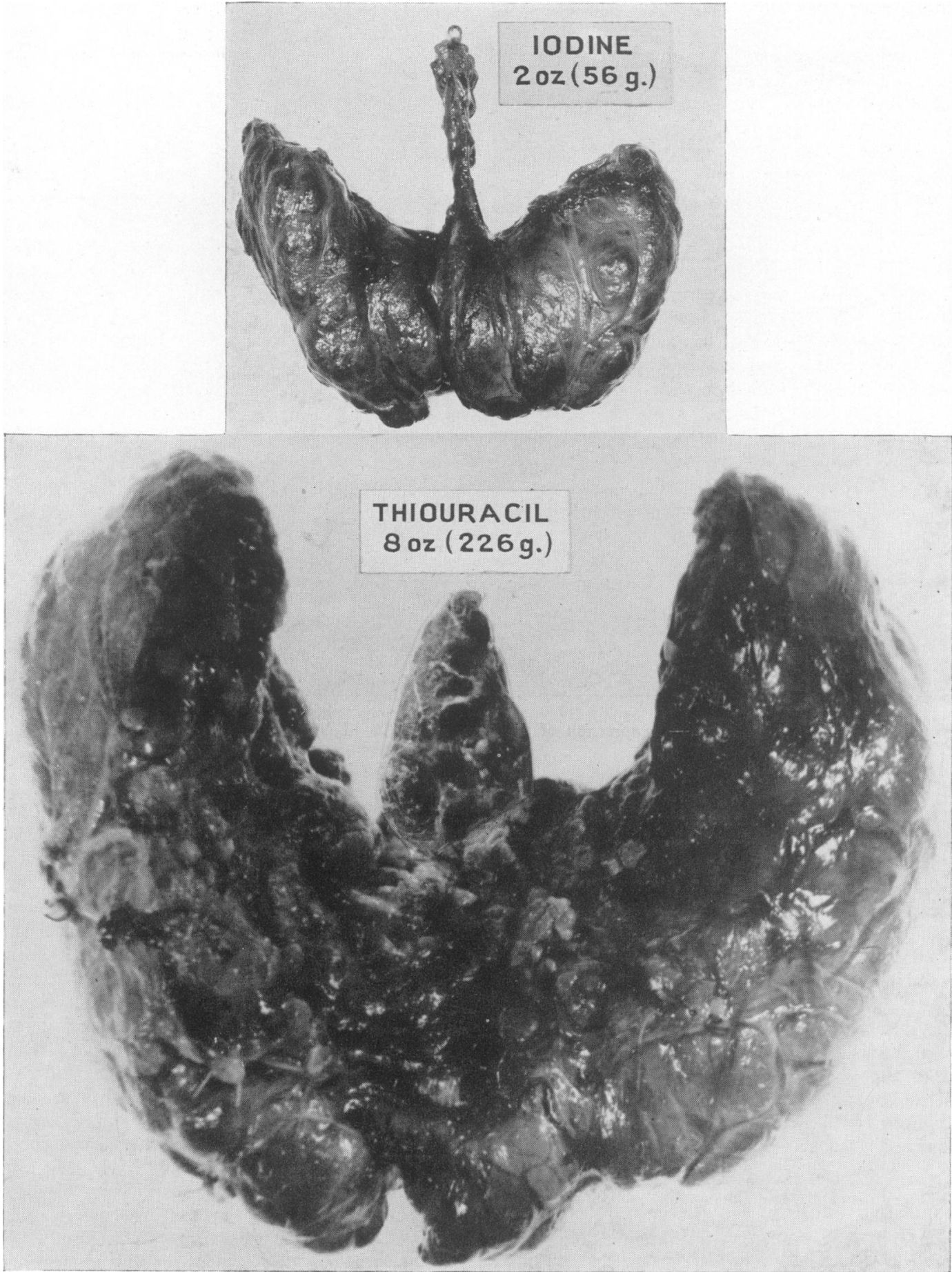

FIG. 5 ( $a$ and b).-Contrast in size between iodine only prepared gland (a) and thyroid gland prepared with iodine and thiouracil (b). 
nection a formal differential count-unless the polymorphs are alarmingly scanty-is unnecessary and time consuming. It is a simple matter for an experienced pathologist to tell from a smear, almost at a glance, whether the granulocytes are plentiful or not. If the granulocytes are scanty it will be wise to abandon thiouracil therapy altogether; after the blood count returns to normal the patient should be put on to iodine and followed up with a thyroidectomy. If the granulocytes are plentiful after a toxic reaction, it is sufficient to wait a week and then to switch to another anti-thyroid agentfor example from methyl to propyl thiouracil. Toxic effects-once they have subsided-with the exception of persistent leucopenia, do not contraindicate the continuation of treatment. In using the term leucopenia it should be borne in mind that an absolute polymorphonuclear count which is a neutropenia for one person is not necessarily a neutropenia for another. The interpretation of the term must be related to the pretherapy normal count-hence the importance of this count for purposes of comparison subsequently. Thus, a patient with a normal high count of, say, 5,000 polymorphs which drops to 1,500 polymorphs is to be regarded more seriously than a patient with a low normal of, say, 3,000 polymorphs which drops to $I, 500$, the first representing a drop of 70 per cent. and the second a drop of 50 per cent.

\section{Thiouracil Goitre and Myxoedema}

High dosage-if prolonged-will produce a thiouracil goitre (Fig. 3 ).

It is very undesirable that overdosage with antithyroid agent should occur. The resultant ' thiouracil goitre' may cause pressure symptoms and force surgery while the gland is still enlarged and vascular and so greatly increase the technical difficulties of the operation (Fig. 4). The thickening of the vocal cords which takes place in the myxoedematous phase also constitutes a very real post-operative danger from oedema of the glottis. Tracheotomy was required in three patients operated upon at the Lahey Clinic during the myxoedematous phase (Cattell, 1949).

Furthermore in spite of what has been written to the contrary my experience is that an irreversible state may be set up if myxoedema is produced by anti-thyroid agents or at least a state which takes a long time to adjust itself. In addition it complicates the surgeon's decision as to how much thyroid to remove at operation and post-operatively seriously retards the patient's return to normal health and thyroid function.

\section{Bleeding}

Thiouracil produces effects upon the gland of primary toxic goitre which only occur minimally or not at all in the nodular thyroid of the older patient. It increases the size of the gland, renders its consistency hard and rigid and so restricts its mobility at operation and increases its vascularity many times (Fig. 5a, b).

It is important to be aware of these effects, $\stackrel{\vec{F}}{\stackrel{\vec{S}}{+}}$ and so prepared for the very severe bleeding which can occur at operation. If this comes as a surprise it may well extend the most experienced surgeon. Much can be done to diminish the technical difficulties associated with the altered physical state of the gland (i) by careful preparation with iodine, (ii) by avoiding pre-operative overdosage with thiouracil and (iii) by a sense of timing in the choice of the optimum moment for the operation, but despite observing these precautions there will still be occasional cases calling for all the operator's skill if bleeding is to be controlled, an adequate amount of gland removed and no damage inflicted upon either of the recurrent laryngeal nerves.

\section{Dosage}

Growing experience shows that there is little to choose between methyl and propylthiouracil. They both produce the same effect in the same dosage, in the same time and with much the same reaction rate. It seems probable that the earlier doses used were too high-the maximun initial dosage should not exceed $200 \mathrm{mgm}$. twic a day and in many cases an excellent response will be obtained from half this dose (Figs. 6 and 7). Because of its availability methyl thiouracil has been used in this country more than the propyl compound and perhaps for this reason acquired a reputation for having a higher toxic reaction rate; in practice there is little difference in the respective reaction rates, approximately one in five patients showing some toxic manifestation. It is, however, worth bearing in mind that a patient who is sensitive to one form of anti-thyroid agent may respond normally to another, for example to Mercazole (I methyl: 2 mercaptomidazole-average comparable dosage, 2 to $4 \mathrm{mgm}$. b.d.), so that after a brief interruption treatment may be continued with safety.

\section{Administration-General Management}

Thiouracil can be used in combination with surgery as a pre-operative agent with a view to bringing the patient to a safe operative level, or its administration can be prolonged with a view to obtaining stabilization without operation-chemical thyroidectomy so to say.

In-patient treatment is advisable for all cases at the outset but this can give way to treatment as an out-patient as soon as the patient seems well and strong enough to make the necessary journeys to 


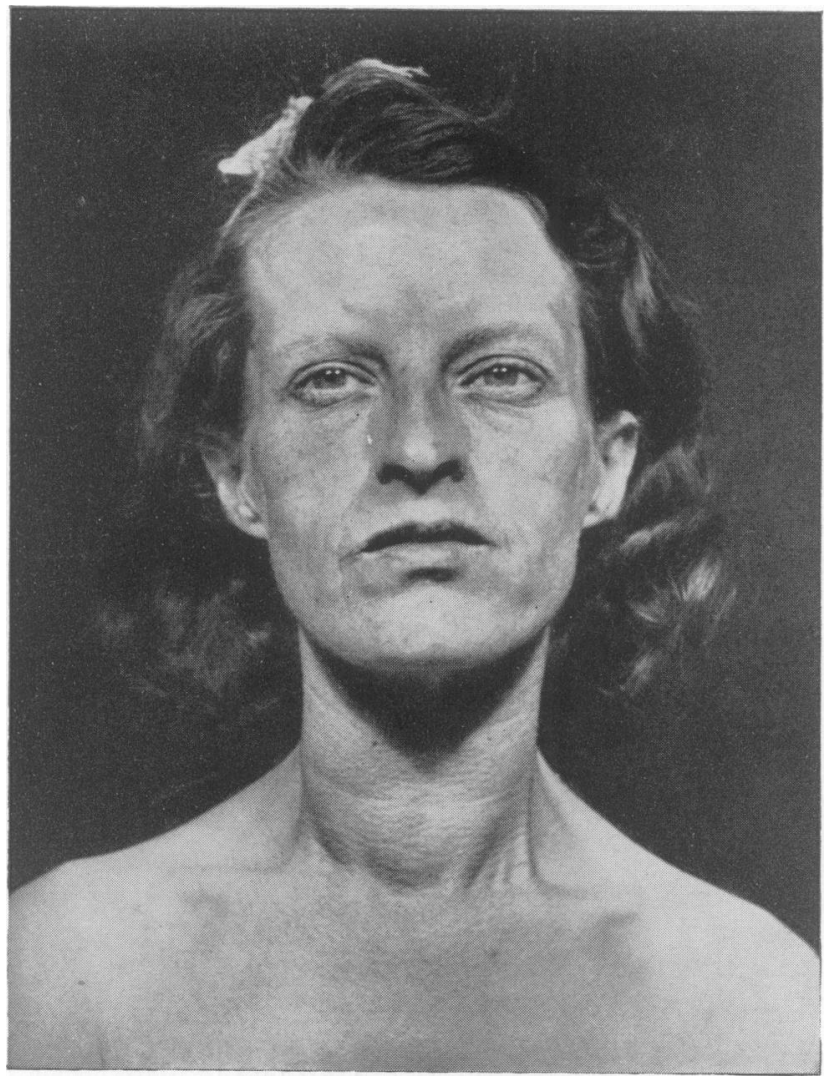

attend regularly, i.e. at weekly intervals at first, though this period can be lengthened as the course proceeds.

\section{To Medical Cases-Thiouracil as a Permanent Stabilising Agent}

The initial management of all patients is the same; the patient is admitted for a period of observation during which, apart from a general examination, a pre-therapy B.M.R. and a 'baseline' differential W.B.C. are done, the weight taken, the neck measured and X-rayed to exclude deviation or compression of the trachea and retro-sternal goitre, and cardiological and other opinions obtained when in doubt. All toxic patients should, in addition, be interviewed by a mature and sympathetic almoner, and in exceptional cases by a psychiatrist, so that we may be familiar with the home housing conditions and other relevant social and personal factors. After the first few days of the resting phase most patients should be allowed to go to the bathroom and to get up for a short time each evening.

Having weighed all the available data the selected anti-thyroid agent is started and continued in its initial dosage until the patient is symptom free. Progress is assessed by observing an improvement in the patient's general clinical condition-usually first noticed at the end of ten days-by a fall in the B.M.R. and pulse rate, and by an increase in weight. When symptom free the dosage is halved and gradually reduced during the course of the next three months, after which a smaller or maintenance dose is substituted and maintained for a minimum period of six months. If at the end of this time the patient remains symptom free the thiouracil is stopped and the patient provisionally discharged with instructions to report for reassessment in three months' time or before if there is a recurrence of the thyrotoxic symptoms. If this regime is followed, few patients will or 


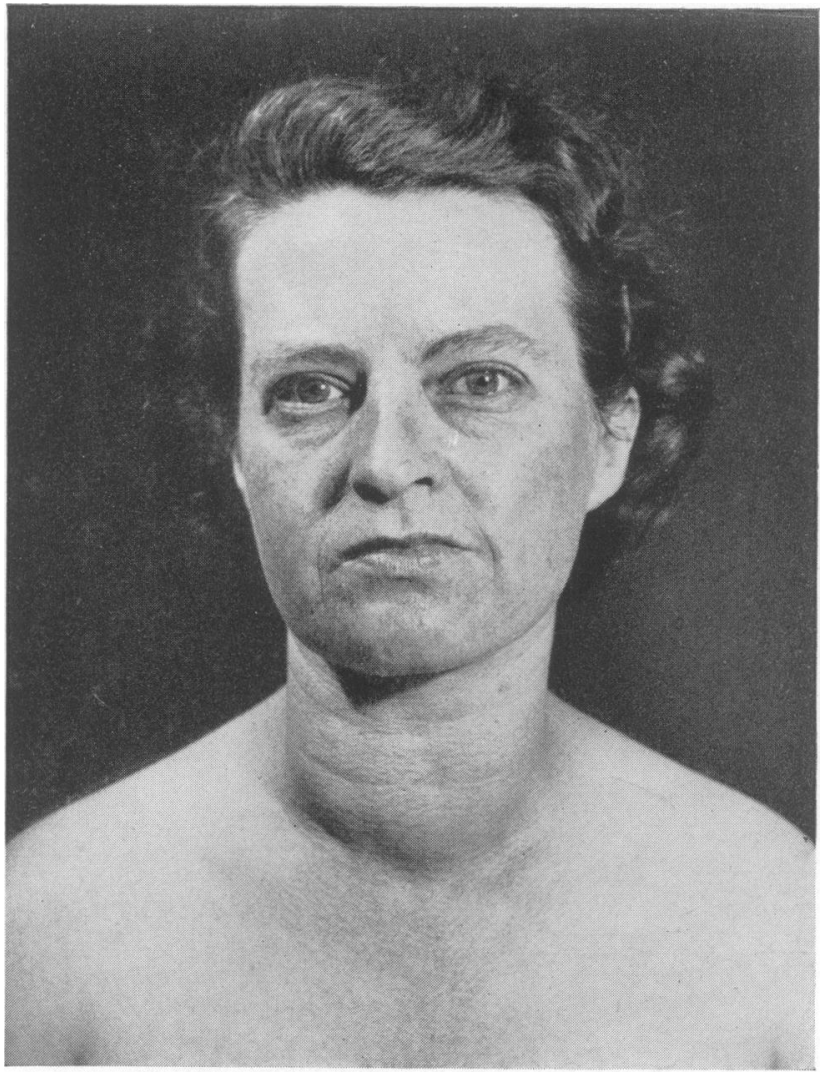

FIG. 7.-Thiouracil therapy. The same patient after six weeks on methyl thiouracil to show the optimum response to this anti-thyroid agent.

should be free from supervision and therapy in less than one year.

While thiouracil treatment is continuing it is usual, although not essential, to have a white cell count at fortnightly intervals. A second B.M.R. estimation during the course of therapy may also be a useful guide to the duration of therapy and occasionally may give valuable warning of impending hypothyroidism.

An initial pre-therapy white cell count below 3,000 associated with neutropenia contra-indicates treatment with thiouracil.

\section{Relapses}

So far as it is possible to judge, approximately half the patients on thiouracil alone relapse following the first full course of thiouracil and a substantial number of those that relapse, relapse again following a second course. The inference is that the relapser goes on being a relapser with repeated courses, but it is only fair to say that of those that relapse a proportion only are thiouracil failures and others relapse because of the persistence of the original precipitating factor such as domestic or financial worry.

Relapses, if they are going to occur, tend to happen quickly, i.e. within two to four months of stopping treatment. Short courses of thiouracil are followed by a high relapse rate, so that treatment with anti-thyroid agents must be continued for a substantial period-not less than six months after the patient has become symptom free.

The permanency of the remission induced by thiouracil is not yet known, as thiouracil therapy has only been available since 1943 , nor is it known if its carcinogenic properties in certain animals will ever produce cancer in man. Time alone will decide these points for us.

To Surgical Cases-Thiouracil as a Temporary Stabilising Agent

The initial procedure when using thiouracil as a pre-operative agent is the same as for medical cases. Administration continues until the patient is symptom free, or ideally, just short of this point when the drug is stopped altogether. 

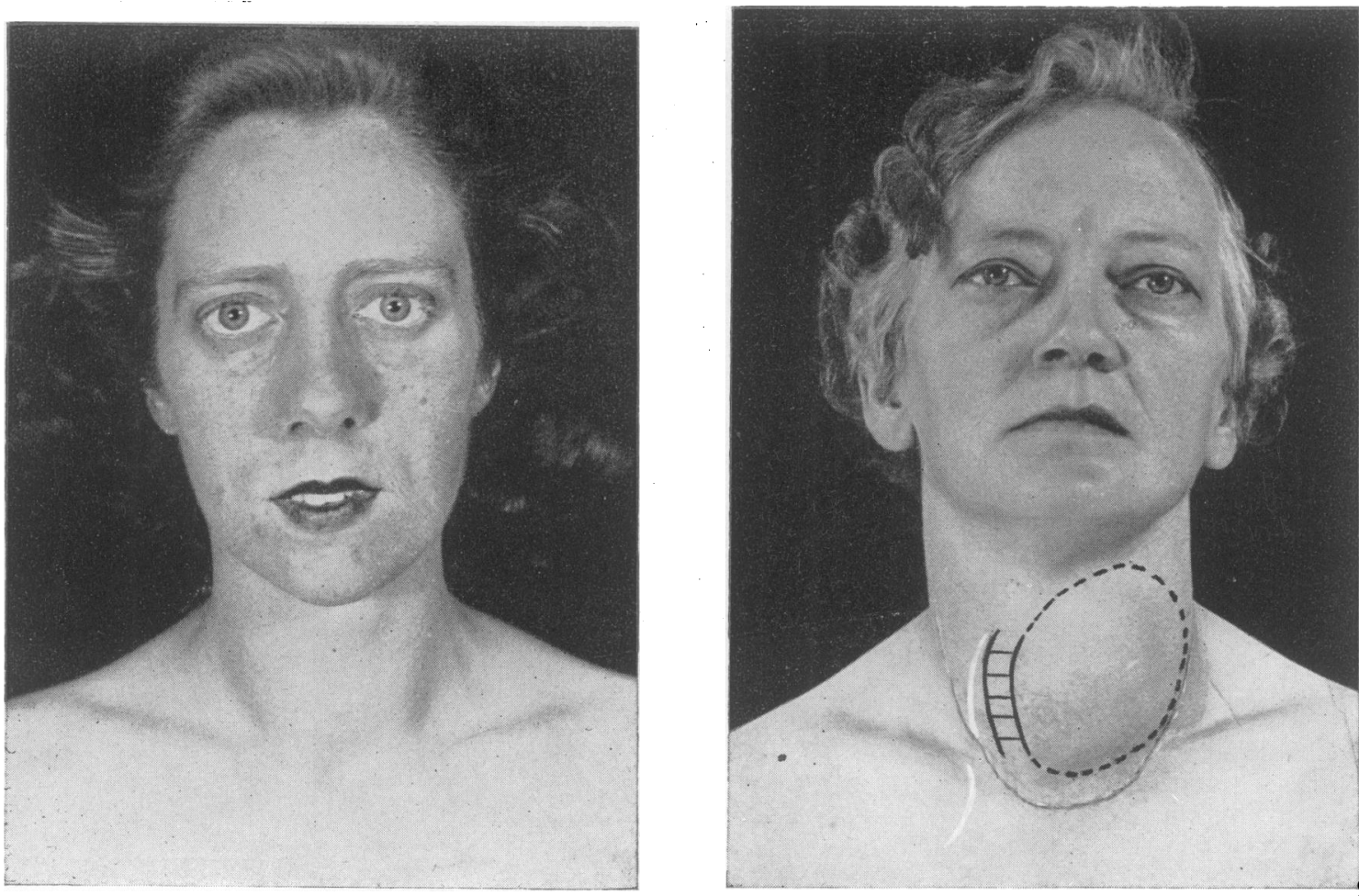

Fig. 8.-Mild thyrotoxicosis. Full and lasting recovery with sedation, rest and change of occupation.

In cases of primary thyrotoxicosis, if the thiouracil therapy before operation has been prolonged, iodine (minims $x$, t.d.s. in milk) should be given for a period of at least three, and sometimes four, weeks-the first two of which can overlap with the last two weeks of the thiouracil therapy. The usual short course of 10 to 12 days is sufficient in cases of toxic nodular goitre as they have not the same tendency to bleed. Those patients who have been receiving the terminal part of their thiouracil course as out-patients may with advantage begin their pre-oferative iodine before they return to hospital, which should be not less than three days before the anticipated day of operation.

Delayed thiouracil reactions have been reported so that it is wise to wait a week after the termination of thiouracil therapy before operating and this interval has also the advantage of enabling the iodine to produce its full devascularizing effect, which cannot be achieved in ten days. Finally, a post therapy pre-operative white cell count should be carried out on the day before operation to exclude a delayed leucopenic reaction. In calculating the optimum day for operation it is important not to forget to take into consideration the date of onset of the next menstrual period. figs. 8-16 opposite side.

Differences in Response-Clinical Improvement. Clinical improvement, which occurs more rapidly in primary than in secondary toxic goitres, is manifested by an abatement of the symptoms, an increase in weight and a fall in the sleeping pulse rate. The B.M.R. averages a drop of a point a day in primary and a point every other day in secondary toxic goitres, so that a patient with primary thyrotoxicosis and a B.M.R. of plus 42 who is to have a thyroidectomy can be told that it will take about six weeks to prepare her for operation.

\section{Definitive Treatment}

\section{THE THREE GROUPS}

When faced with a thyrotoxic patient, who may be young or old, who may be with or without enlargement of the thyroid gland and with or with- os out the classical features of the disease, it can be $N$ perplexing to make up one's mind as to the most suitable definitive line of treatment.

In practice it will be found that the majority of thyrotoxic patients when first seen can be divided into three groups:

A medical group in whom there is present a special indication for medical treatment.

A surgical group in whom there is present a special indication for surgical treatment. 


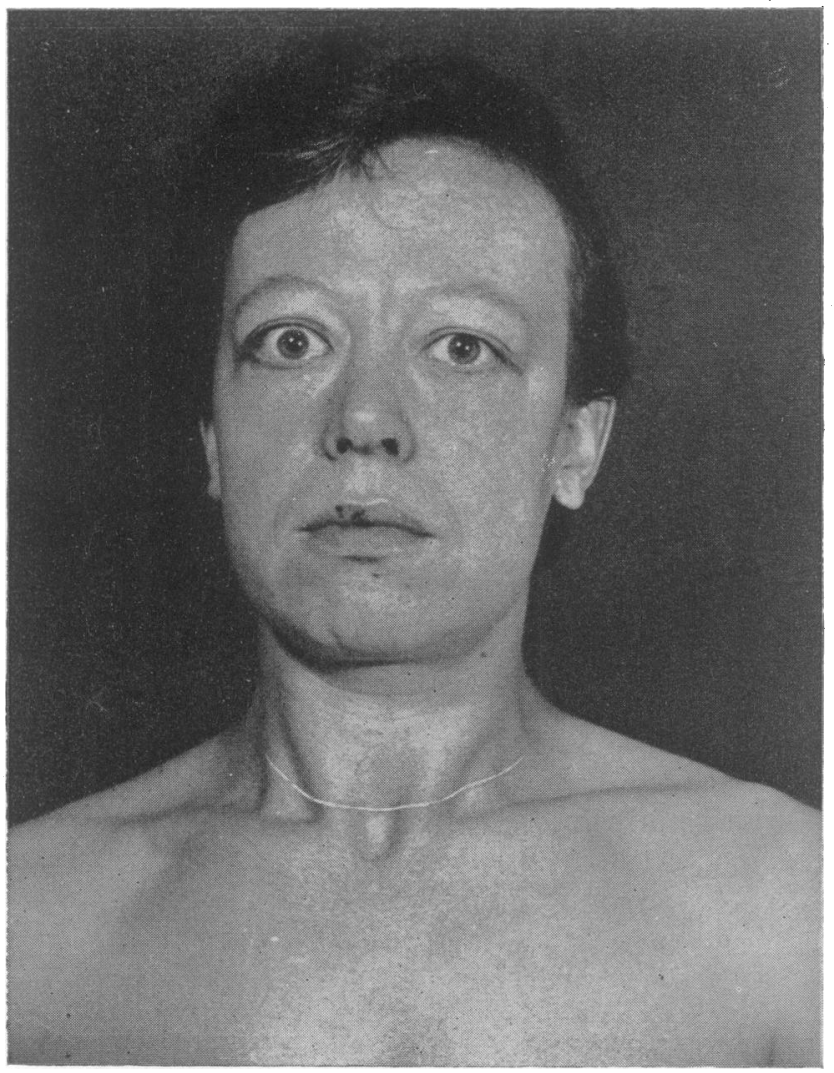

A residual group in whom the method of treatment can only be decided after a period of trial with the anti-thyroid agents.

In arriving at a decision as to the appropriate line of treatment in an individual case it is helpful first to exclude those patients who for purposes of therapy fall naturally into a medical or surgical category. Let us consider first those in whom medical treatment is indicated.

\section{Group I. Medical Treatment-The Indications}

(i) Mild Thyrotoxicosis (Fig. 8). Medical treatment is indicated in all patients with mild thyrotoxicosis, that is to say, those with a B.M.R. of plus 20 and a pulse rate of not more than 90 . The usual methods of rest and sedation will suffice for the majority; a few will require thiouracil ; surgery is absolutely contra-indicated.

(ii) Recurrent Thyrotoxicosis. Recurrent thyrotoxicosis might be regarded as the cardinal indication for the use of thiouracil although radio-iodine is now available for the same purpose. $\mathrm{Re}$ operation on these patients is always hazardous because of the risk of damaging either or both inferior laryngeal nerves (Fig. 9). Thiouracil is $\underset{\vec{P}}{\vec{P}}$ also of particular value in treating patients with a $\frac{0}{3}$ unilateral recurrence associated with a recurrent $\vec{\partial}$ laryngeal nerve palsy on the side opposite to the recurrence (Fig. IO). If the recurrence takes place on the side of the nerve lesion re-operation can be considered with less anxiety as the underlying nerve has already been damaged.

(iii) Age-Stress and Other Factors. Medical treatment should be employed whenever possible in young children (Fig. II) and in the elderly 응 (Fig. 12) and at times of exceptional physiological stress such as puberty (Fig. I3), pregnancy (Fig. 14) 을. and the menopause (Figs. I5 and I6), when thiouracil cover will generally be all that is neces- o sary. In the case of thyrotoxicosis associated with $N$ pregnancy it should be stated that it is unnecessary to interrupt the pregnancy. The danger of pro- $O$ ducing sub-thyroid babies as a result of thiouracil therapy during pregnancy appears to have been $\frac{0}{\Phi}$ greatly exaggerated, but iodine should replace the thiouracil for the last four weeks before delivery. 0 In those few cases in which the prospective mother does not tolerate the anti-thyroid agent, 


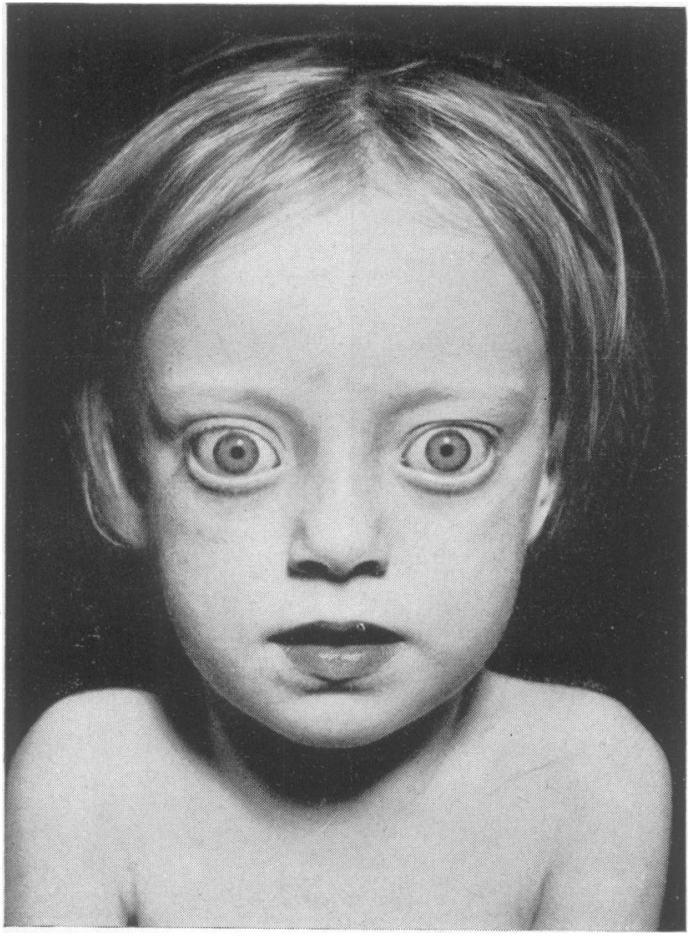

FIG. I I.-Thyrotoxicosis in a child of three; treated with thiouracil; now aged eight and symptom free.

thyroidectomy during pregnancy after iodine preparation may have to be carried out. The thiouracils are secreted in the milk so that it is wise either to wean the child after birth or to continue with only very small doses to avoid cretinism.

Medical treatment will also be the elective initial method in patients in whom thyrotoxicosis is complicated by an anxiety state; in patients in whom a precipitating causal agent is discovered and can be removed, whether it be physical such as a septic tooth or tonsil or even a carcinoma of the breast, or mental, for example financial worry or housing difficulties; in post-menopausal patients in whom the thyrotoxicosis is unassociated with pressure symptoms, undule nodularity or cardiovascular effects; in certain cases of malignant exophthalmos; in poor operative risks and when expert surgery is unavailable or refused.

\section{Group 2. Surgical Treatment-The Indications}

Surgery, as the primary definitive line of treatment, is indicated when pressure symptoms are present as shown by displacement or compression of the trachea, or when symptoms of pressure might be precipitated by the use of thiouracil as in a retrosternal or intrathoracic goitre (Fig. 17).

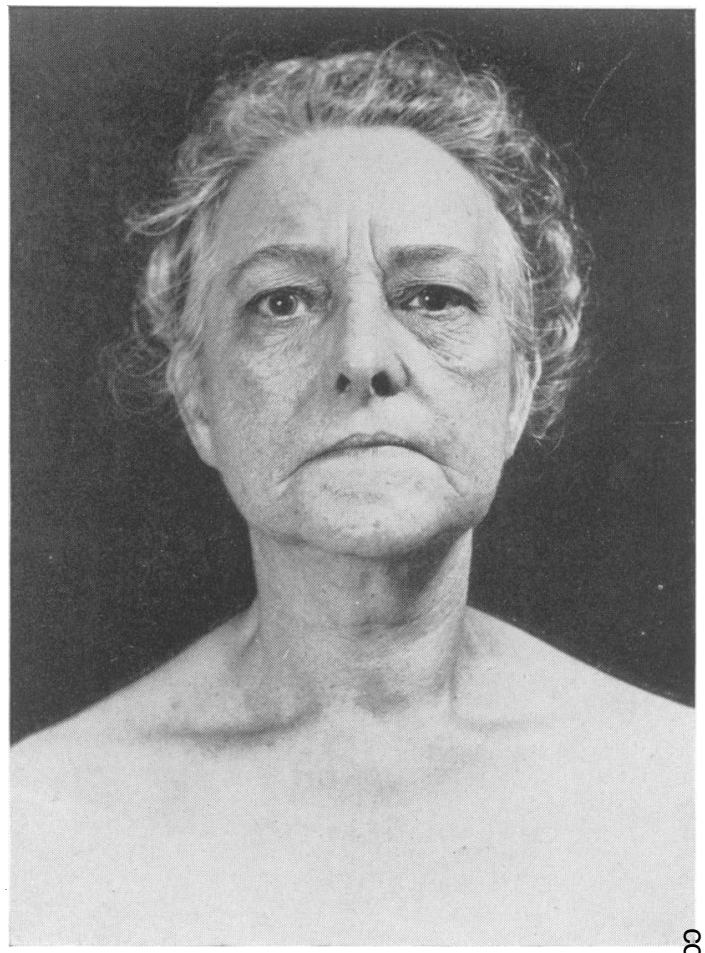

FIG. 12.-Thyrotoxicosis in the elderly; no auricula fibrillation; stabilized on thiouracil.

It is also generally agreed that surgery is advisable in patients with auricular fibrillation or other cardiovascular disturbance attributable to the thyrotoxicosis (Fig. I 8). Surgery may also be the most desirable method of treatment in those who are unable or unwilling to attend regularly, in the unreliable and unco-operative, for social or economic reasons and for reasons of size or nodularity or because malignancy cannot be excluded. By a process of elimination it also becomes the only effective expedient in those patients in whom medical treatment has failed, i.e. the thiouracil sensitive, the thiouracil relapses and the thiouracil resistant. There is no reason to withhold antithyroid agent in the pre-operative preparation of toxic patients in the surgical group provided that it is administered under close supervision and followed by iodine in the usual way. In many instances there may be a very satisfactory response to anti-thyroid agents and in approximately onethird of the cases of auricular fibrillation of thyrotoxic origin normal rhythm will be restored.

\section{Group 3. Residual Group}

The exclusion of patients in the two previous groups leaves us with a large residual group, all of 


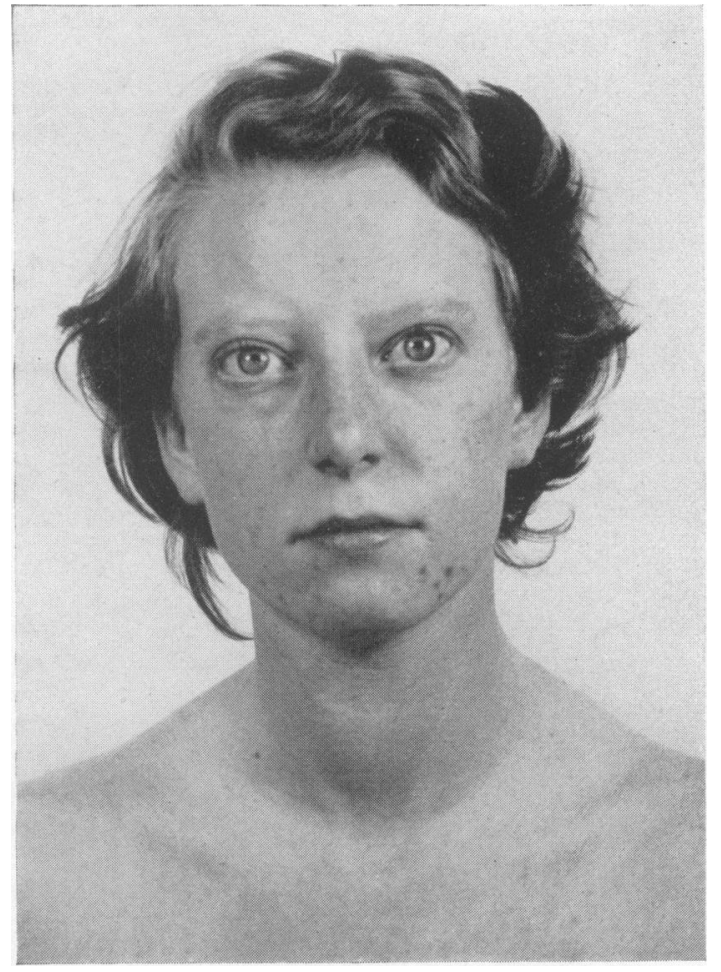

FIG. 13.-Thyrotoxicosis in puberty and adolescence (age 17). Undergoing treatment with thiouracil.

whom have moderately severe thyrotoxicosis (pulse rate 90 to 120 ) or severe thyrotoxicosis (pulse rate above 120). This is a group of mixed thyrotoxics, some primary, some secondary, in whom there is no clear-cut indication as to whether they would be best treated by medical or surgical methods. If we treat all patients in this group surgically, then we shall automatically operate upon a number who might have been cured medically. If we treat all patients in this group medically for an indefinite period of time we are going to submit a considerable proportion to a prolonged and eventually fruitless course of therapy.

The difficulty is that at the first examination we have no way of predicting which patients will be stabilized by anti-thyroid agents and therefore could be excluded from surgery, and which patients will relapse after medical treatment and would therefore be better prepared for surgery from the outset. Accordingly all patients with severe or moderately severe thyrotoxicosis who do not naturally fall into the medical or surgical categories mentioned should be submitted to a course of anti-thyroid agents in order to determine their response to the drug.

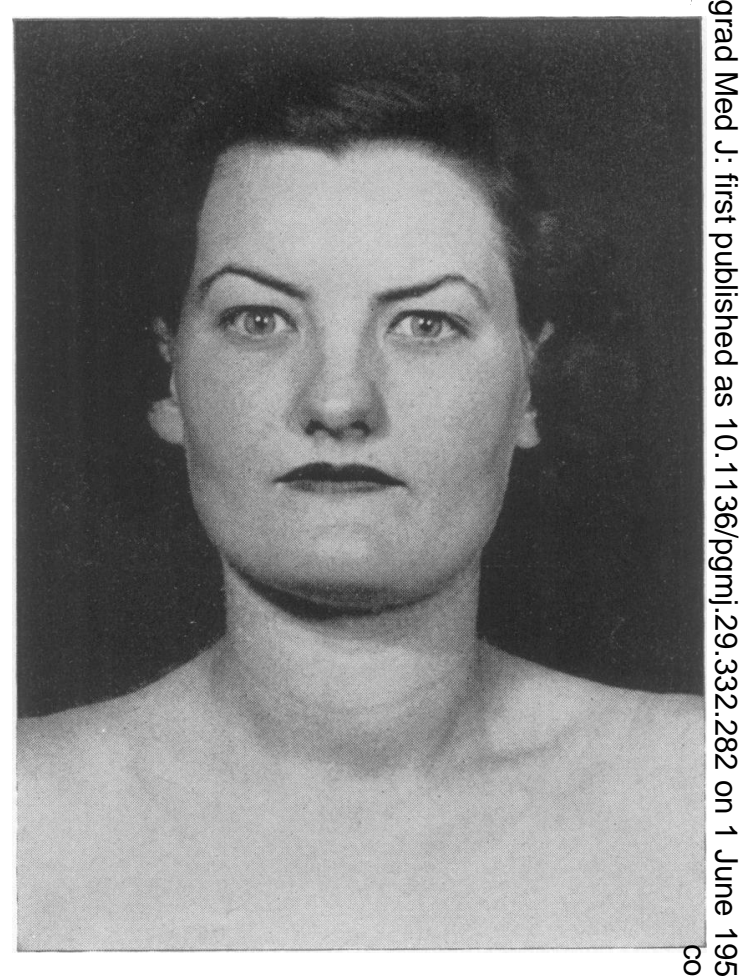

FIG. 14.-Thyrotoxicosis in pregnancy; thiouracif. cover during pregnancy. Post-partum relaps on withholding anti-thyroid agent; sub-totat thyroidectomy after weaning baby.

\section{Therapeutic Trial}

The procedure recommended is as follows: Give to all patients in the residual group a therapeutic test course of thiouracil for a period not exceeding one month or until symptom free, whichever is the earlier. The situation should then be reassessed. It is at this early stage that the position of all these patients should be reviewed and not after months of thiouracil treatment. Excluding those who fall out because they are thiouracil sensitive two groups will be found to emerge for reassessment-a small group which responds indifferently and a large group which responds well to thiouracil.

The Thiouracil Resistant or Dilatory. This N group consists of patients who respond slowly to N thiouracil and are dilatory in showing clinical im- $\omega$ provement at the end of the trial period. Experience suggests that the majority of these re- $\frac{0}{\bar{D}}$ fractory patients will never become completely $\stackrel{\Phi}{\rightarrow}$ symptom free on the anti-thyroid agents at present available, however prolonged the use of these drugs may be. 


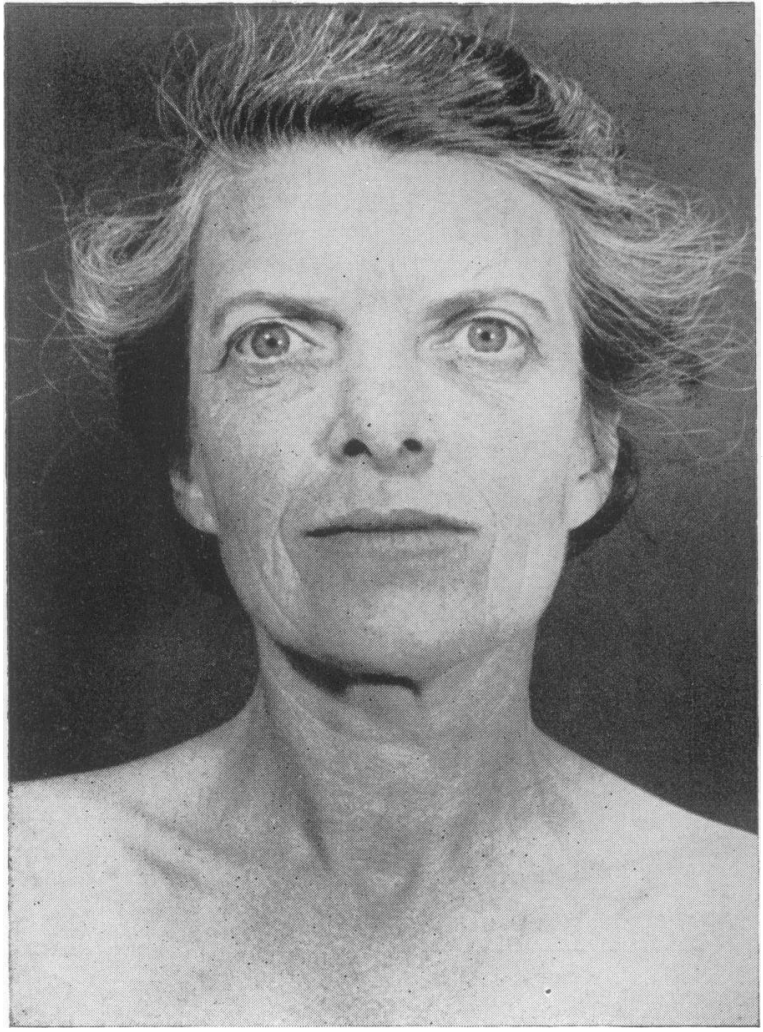

FIg. I 5.-Thyrotoxicosis at the menopause; before treatment with thiouracil.

If any doubt still remains a further four weeks' thiouracil therapy should be given and if at the end of this time they remain refractory the thiouracil should be stopped, iodine started and operation carried out as soon as the maximum response to the iodine has been obtained.

\section{The Thiouracil Responsive}

Patients who respond quickly to thiouracil will be found at the end of the four-week period to show a marked clinical improvement. Once again it is at this early stage that a decision should be taken as to whether to continue with medical treatment or abandon it in favour of surgery. It might be argued that there is no decision to take and that all patients who show a favourable initial response should be treated along medical lines until they are stabilized or fail to respond any longer to the drug. This is the tendency in some centres but is an attitude which fails to take into consideration the varying demands of the different age groups and the influence of social and economic factors upon the course of the disease. Thoughtful surgeons operating upon the thyroid today are

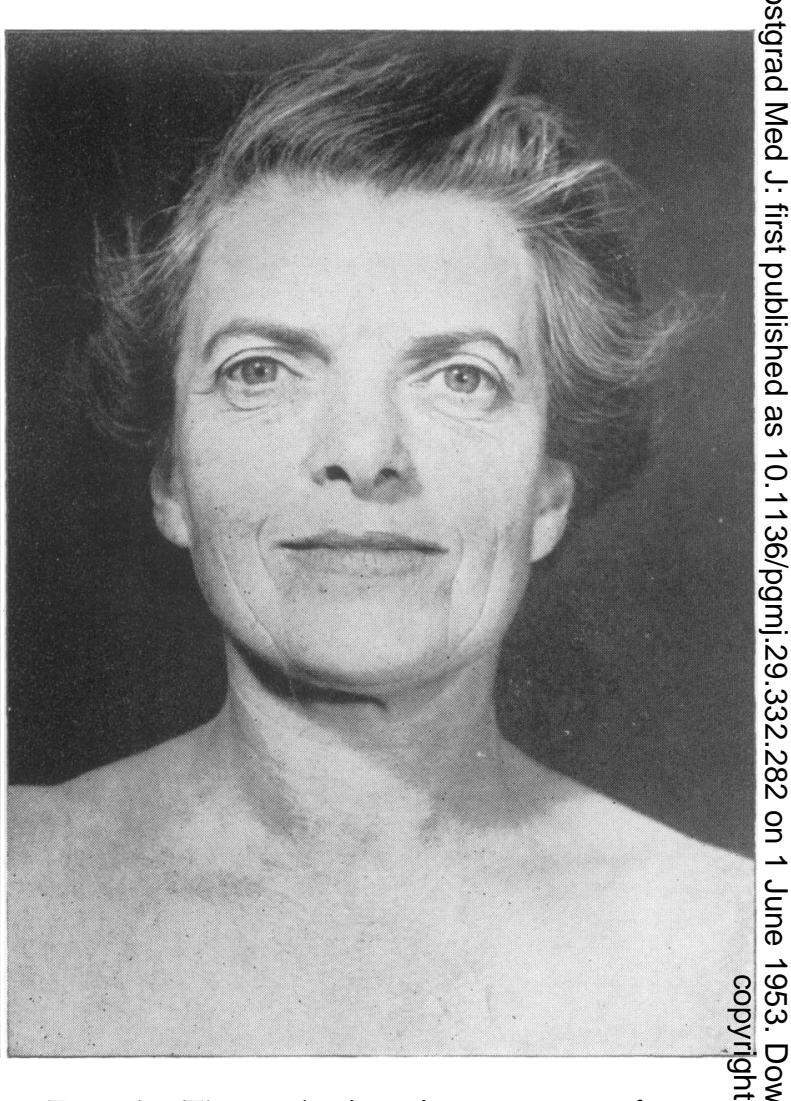

FIG. I6.-Thyrotoxicosis at the menopause; after treatment with thiouracil.

fully aware of the value of thiouracil and give it $\stackrel{\varrho}{\Rightarrow}$ full credit but at the same time feel that certain $\vec{O}$ patients in this group should be operated upon just as some others should be encouraged to continue with anti-thyroid therapy only. The decision as to whether the future management of the patients in this group should be along medical or surgical lines can usually be resolved by reference 3 . to the following points: the age, the facilities available, the patient's attitude, the precipitating factor.

Age

Pre-Menopause. Broadly speaking, the younger adult patients should be operated upon; cer- $\sigma$ tainly those under 30 . There is a natural re- $N$ luctance to interfere surgically with the endocrine N system at this age, yet younger patients do not $\omega$ tolerate well the tedium of prolonged thiouracil therapy. They are impatient of results and inclined to find the repeated visits to hospital irksome and boring, and for this reason they may not progress favourably. More important still the younger age group-because the gland reacts 


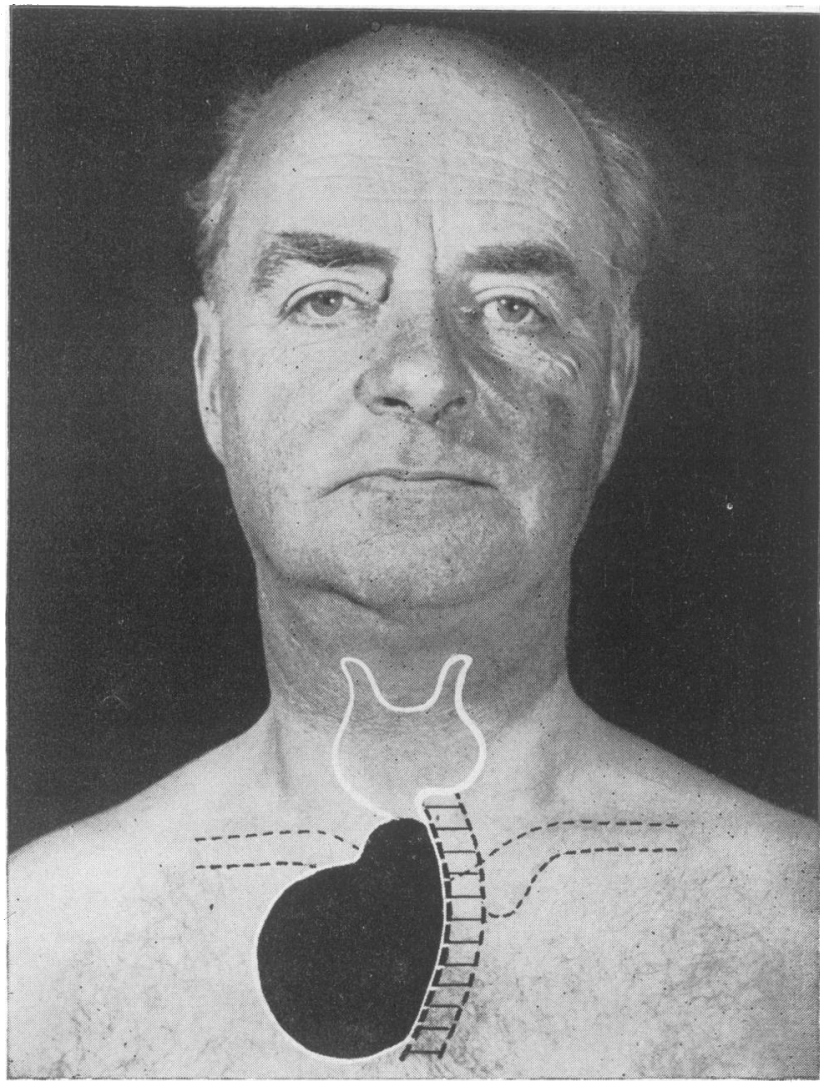

Surgical treatment figs. $17-18$

FIG. 17.-Retrosternal goitre; thiouracil dangerous.

maximally to the anti-thyroid agent-are more liable to develop a thiouracil goitre and quite suddenly to slip over into myxoedema unless very frequent and time consuming visits are made to a thyroid clinic.

Menopausal and Post-Menopausal. In menopausal and post-menopausal patients who are responding well it is wise to avoid thyroidectomy and to persist rather with anti-thyroid agents if these are well tolerated. Commonly a thyrotoxic flare-up during the menopause is a transient manifestation of the disease and will die down as the climacteric comes naturally to its end.

Post-menopausal patients, even if the gland is nodular, respond in my experience in a more satisfactory and lasting manner to anti-thyroid agents than patients in the younger age groups. Operation will be advisable in those showing displacement of the trachea, a retrosternal goitre, or with associated cardiovascular disease or if there is any suspicion of malignancy, although coincidence of the latter with thyrotoxicosis is exceedingly rare. Post-menopausal patients without these complications should be encouraged to persist with the full course of anti-thyroid agent and the subsequent maintenance dose for some months after they have become symptom free.

\section{Facilities'available}

If the surgical facilities available are poor; as they can be, it will be prudent to continue with medical treatment. Only if they are good does surgery become an alternative to medical methods and it should then be carried out immediately the patient has had her pre-operative course of thiouracil and iodine. The medical facilities available can also be poor-by this I mean the time and care the physician concerned is prepared or able to give to the patient. Continued supervision by one man is essential in these mixed diseases of psyche and soma and this demands both time and patience.

\section{The Patient}

Patients with thyrotoxicosis are usually intelligent and their own wishes in regard to treatment must be consulted after the advantages and disadvantages of both methods have 


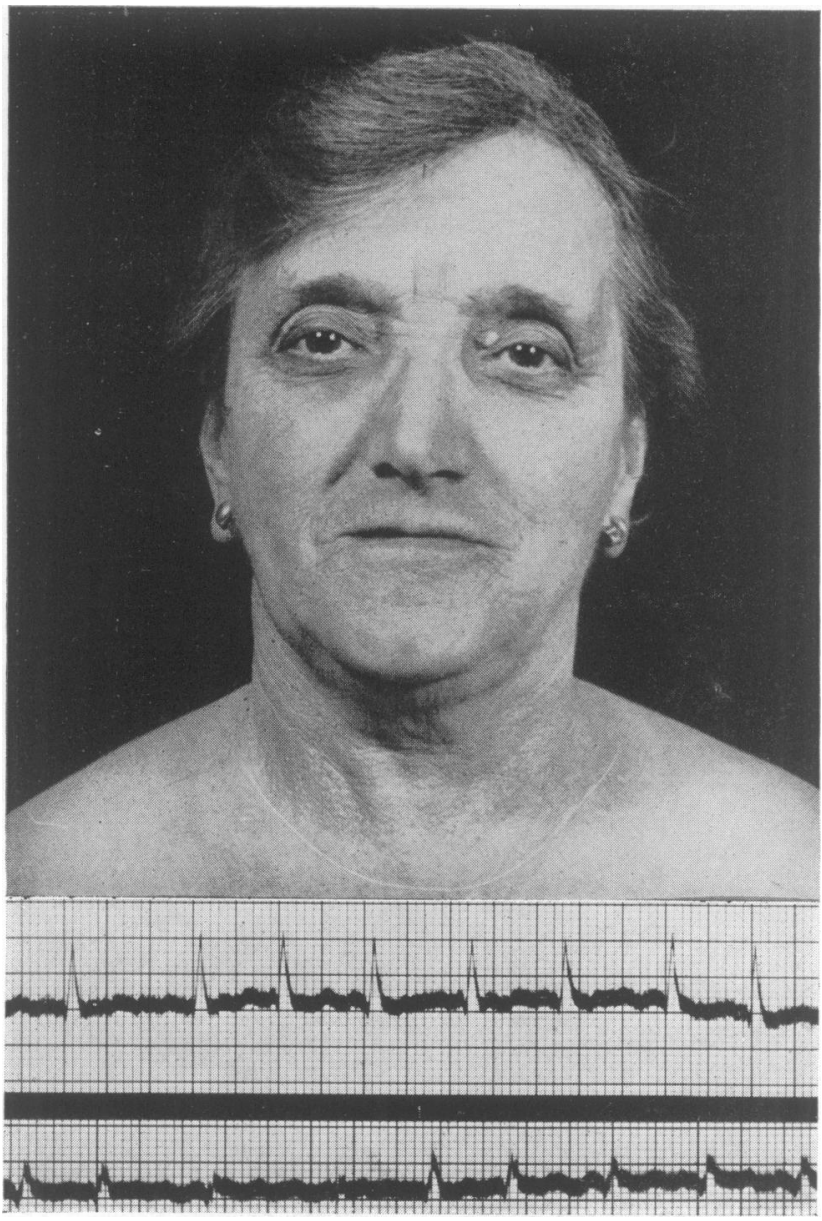

FIG. 18.-Thyrotoxicosis with auricular fibrillation.

been explained to them; for example, the surgical cure is quick and permanent and removes the goitre, but involves an operation; medical treatment may produce relief of symptoms without an operation but a permanent cure is not certain and surgery may be necessary in the end. Some patients find medical treatment tedious and frustrating, others will only show improvement when told that surgery is not contemplated-and so on.

\section{The Precipitating Factor}

If a precipitating factor can be found and removed, the patient will be more than halfway towards a permanent relief of symptoms without any other form of therapy. In searching for such a factor intercurrent illness or disease should first be excluded. Special enquiry should then be made, but in privacy and in the gentlest way, into many supremely personal matters.
Common contributing factors are married unhappiness, - housing difficulties often associated with living with 'in laws,' exhaustion from the prolonged strain either of overwork in the home or nursing a sick relative, the emotional shock resulting from an unhappy love affair or the death of a close friend or member of the family, an unsuitable occupation or financial or domestic worries in their manifold varieties.

It should here be put on record that it is typical of the contrariness of this disease that in more than half the patients no relevant precipitating agent can be found.

If no precipitating factor can be found the case must be treated on its merits; if one is revealed which can be relieved, medical treatment alone may well be all that is necessary. It is in the cases in which there is an obvious domestic or psychological obstacle to recovery which cannot be removed in which the greatest judgment is required 


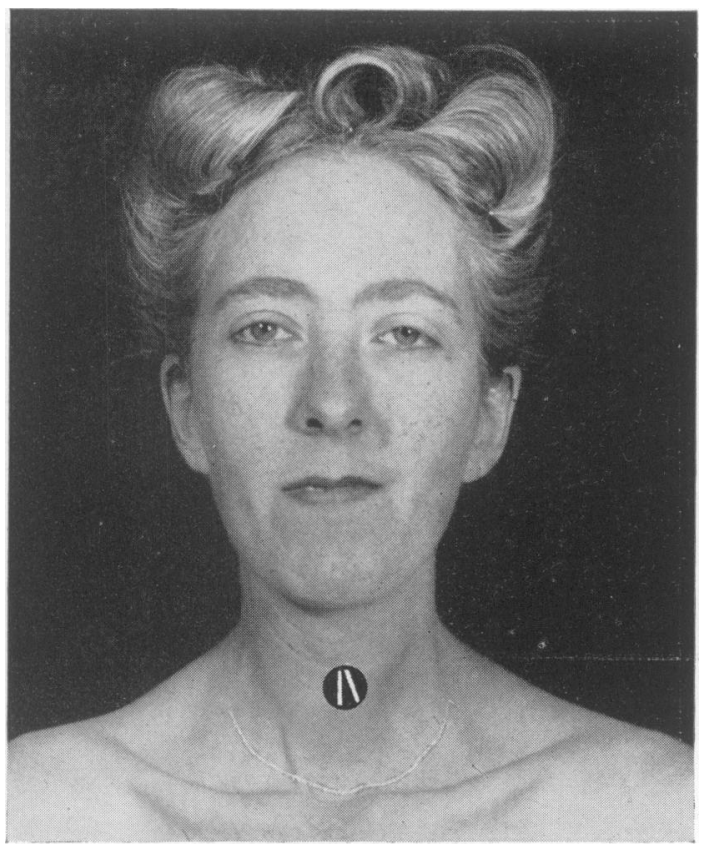

FIG. 19.-Three previous thyroid operations. Symptomless palsy on right side.

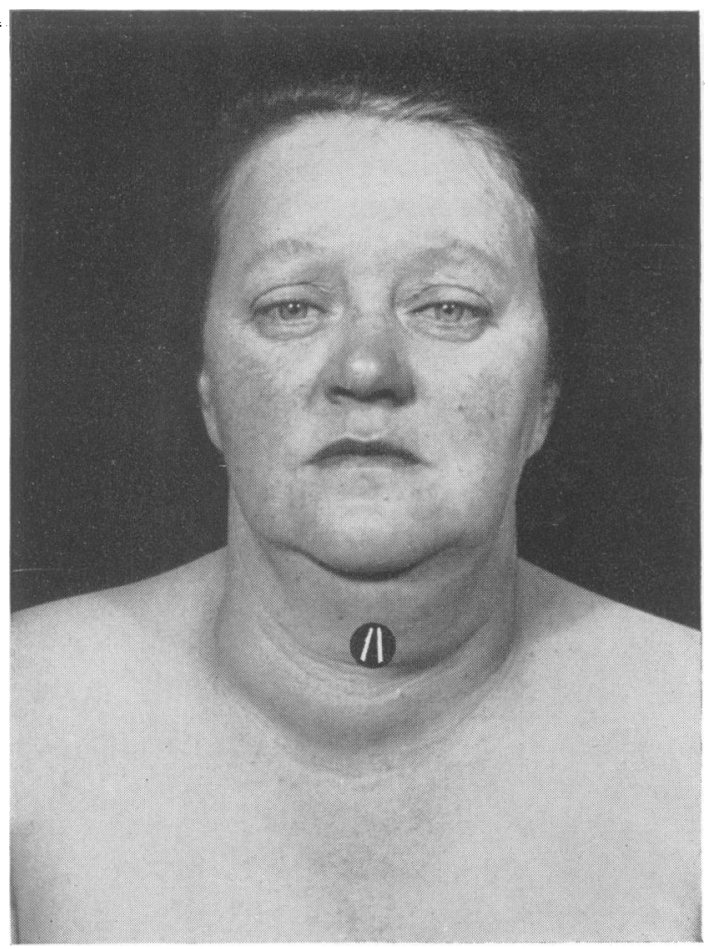

Fig. 2r.-Hashimoto's disease with paralysis of one vocal cord.

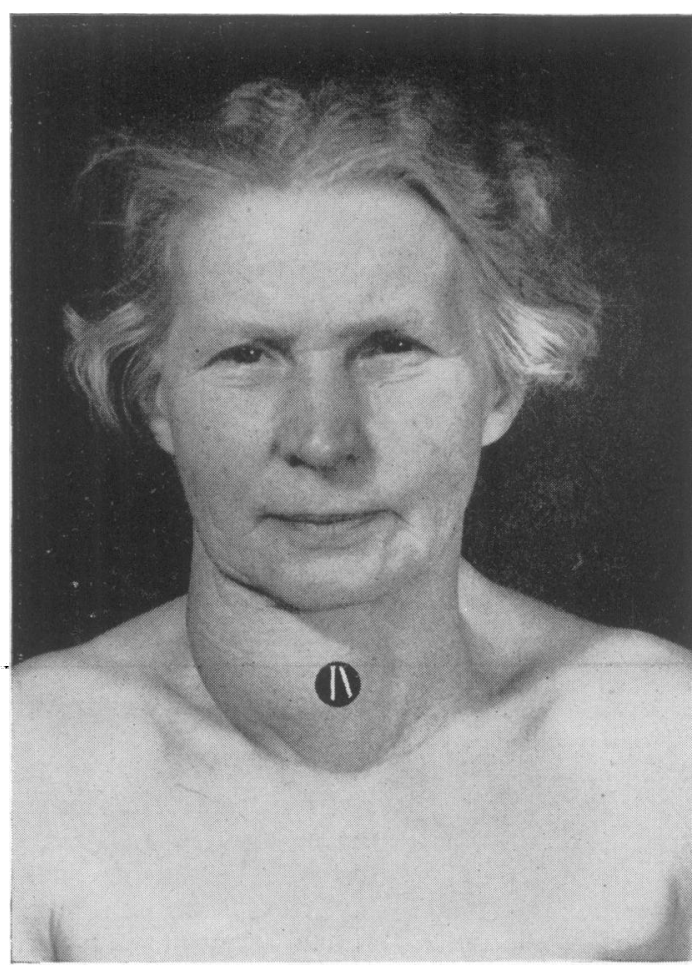

FIG. 20.-Carcinoma of the thyroid with paralysis o the right vocal cord.

in determining the most suitable form of treatment. Such patients will almost certainly relapse if treated with thiouracil alone. In the same way operation is likely to be only partly successful. Sub-total thyroidectomy in these circumstances should, I think, be reserved for the severely thyrotoxic in whom the measure of improvement produced may be sufficiently significant to enable the patients to review and assess their own problems with a fresh outlook and in a more balanced manner. No rules, however, can be laid down, each patient and each problem must be assessed and treated individually.

Iodine Preparation. There is one short rider that should be added to the subject of treatment; some of the younger patients especially do not tolerate thiouracil well and if the thyrotoxicosis is of moderate severity only can be brought to a safe operative level with iodine alone. In selected cases this method of preparation still has a definite place.

\section{Radioactive Iodine}

It is not possible yet to assess the part radioactive iodine is ultimately likely to play in the diagnosis or treatment of thyrotoxicosis. En- 


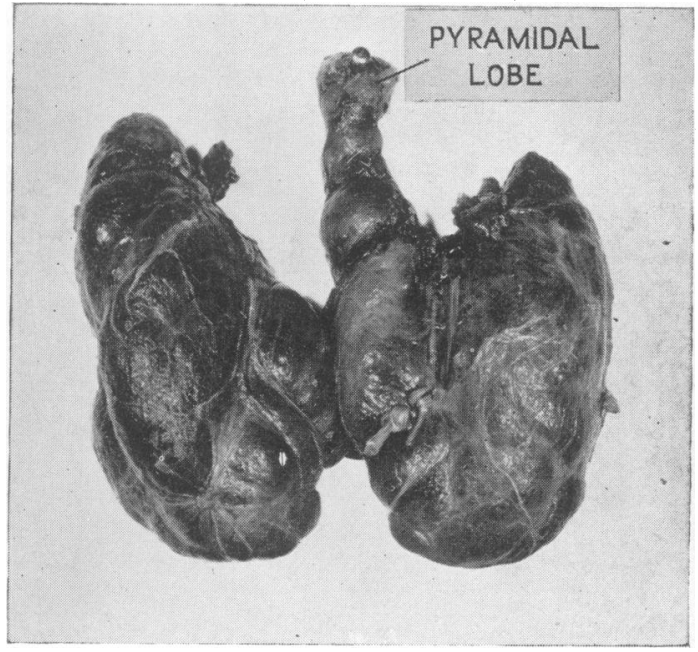

FIG. 22.-Operation specimen showing the pyramidal lobe.

couraging reports have been received from a number of centres. The amount of radioactive iodine present in the thyroid gland itself can be measured by means of a Geiger counter. If the amount of radioactive iodine present in the plasma is determined at the same time, the thyroid iodine clearance rate can be measured and this is of diagnostic value. From here it is removed both by the thyroid and the kidneys. The rate of uptake by the thyroid is related to the activity of the gland, being rapid in toxic goitre and slow in myxoedema. In consequence, during the same period there is proportionately less or more iodine available for excretion by the kidneys and this amount can be measured.

These variations form the basis of tests which can be used for diagnostic purposes to determine the presence or absence of thyrotoxicosis-and is especially valuable in those doubtful cases in which the clinical picture may be complicated by an anxiety state. It is equally useful in determining the degree of hypothyroidism in a case of myxoedema and can be helpful in circumstances when the B.M.R. is likely to be inaccurate.

For therapeutic purposes the dosage is based on the severity of the toxicity and the size of the gland. A single dose is usually sufficient but subsequent smaller doses may have to be given. The very simplicity of the treatment naturally makes it popular with patients. The clinical response normally follows a similar pattern; in the first few days the gland becomes tender, to be followed in the course of the first week by an exacerbation of toxicity. Clinical improvement follows at the end of the first fortnight and in four weeks 97 per cent. of the radioactivity is dissipated.

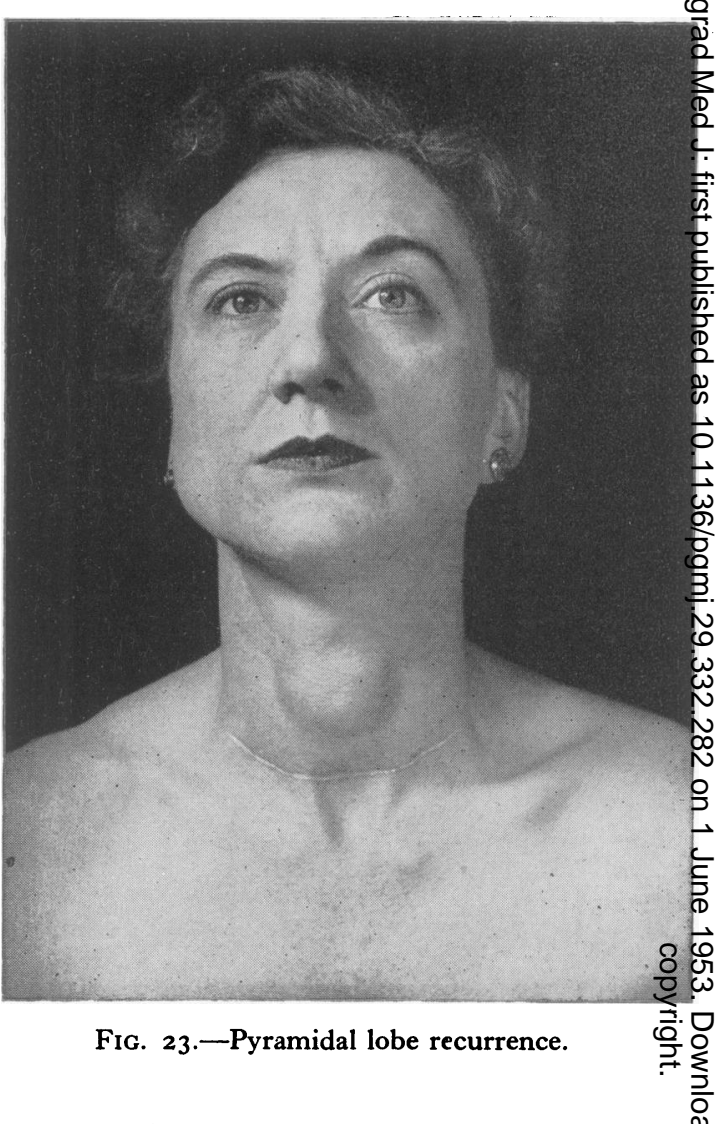

Until we know whether the threats of carcino- ٌ genesis, the kidney or ovarian or bone marrow $\stackrel{\mathbb{Q}}{2}$ damage are real or groundless, it will be wise to $\overrightarrow{\overrightarrow{0}}$ reserve $\mathrm{I}^{\mathbf{1 3 1}}$ for the treatment of patients over the 3 age of 50 , for cases of recurrent thyrotoxicosis and patients who are unsuitable for operation or who are resistant or sensitive to the anti-thyroid agents. In the meantime its potentialities continue cautiously to be explored.

\section{The Vocal Cords}

A routine pre-operative and post-operative laryngoscopy should be done before and after 웅 every thyroidectomy.

Pre-operative laryngoscopy occasionally reveals a paralyzed cord; in some instances this may in- N fluence the surgeon's decision to operate and in others will exonerate him if symptoms develop $N$ subsequent to operation. The examination is of $\underset{\omega}{N}$ particular importance in patients who have had a previous thyroid operation or if carcinoma of the 0

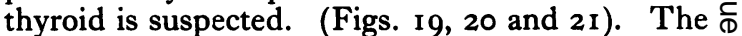
vocal cord changes and associated dangers in $\stackrel{\odot}{+}$

myxoedema have been referred to on p 287 .
Post-operative laryngoscopy is essential if a $\frac{0}{0}$ true estimate of the frequency of vocal cord $\stackrel{\mathbb{D}}{\varnothing}$ 


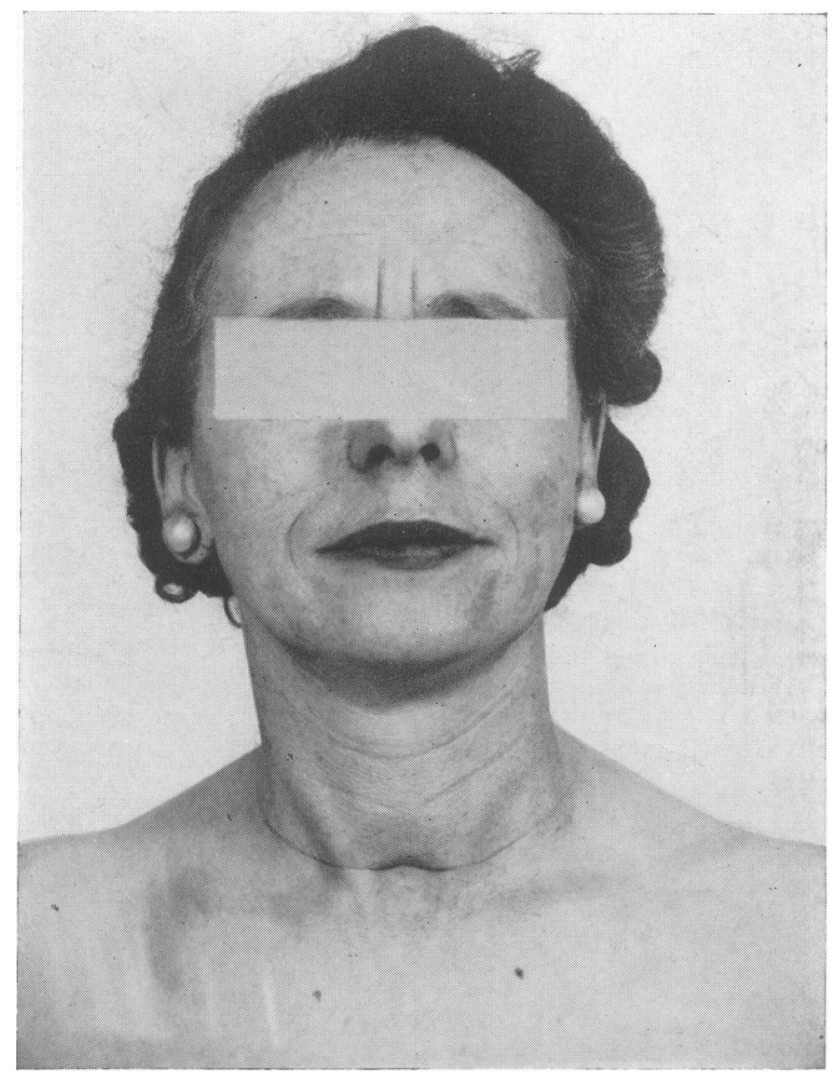

damage following thyroidectomy is to be obtained. Vocal cord paralysis following thyroidectomy is commoner than supposed and its incidence is certainly higher after the 'blind' operation than when the recurrent laryngeal nerve is identified. My own practice is always to identify either visually or by palpation the recurrent laryngeal nerve on one side in a bilateral operation. Existing statistics tend to be based on the selective postoperative examination of vocal cords in those patients only who have hoarseness of voice or other obvious symptoms of recurrent laryngeal nerve damage. This system fails to reveal those cases of unilateral recurrent nerve damage in which symptoms are minimal as a result of rapid compensatory readjustment by the normal cord. There are a considerable number of such cases and there is the danger that it may be assumed that there has been no nerve damage unless we practice a routine postoperative laryngoscopic examination in all patients who have had a thyroidectomy.
The Operation of Thyroidectomy (for toxic goitre)

The operation for thyrotoxicosis-sub-total thyroidectomy - is now practised with a considerable measure of standardization. It is usual to remove approximately seven-eighths of each lobe having tied both superior and inferior thyroid arteries and identified at least two parathyroid glands and one recurrent laryngeal nerve. It is not the purpose of this article to discuss technical details which are far better learnt by watching a general surgeon with special experience in thyroid surgery at work, but attention is drawn to the following points:

I. In my experience it is not necessary to perform a bilateral operation for a unilateral 'toxic adenoma' provided the contralateral lobe is explored and appears normal to inspection and palpation.

2. The pyramidal lobe should always be re- 


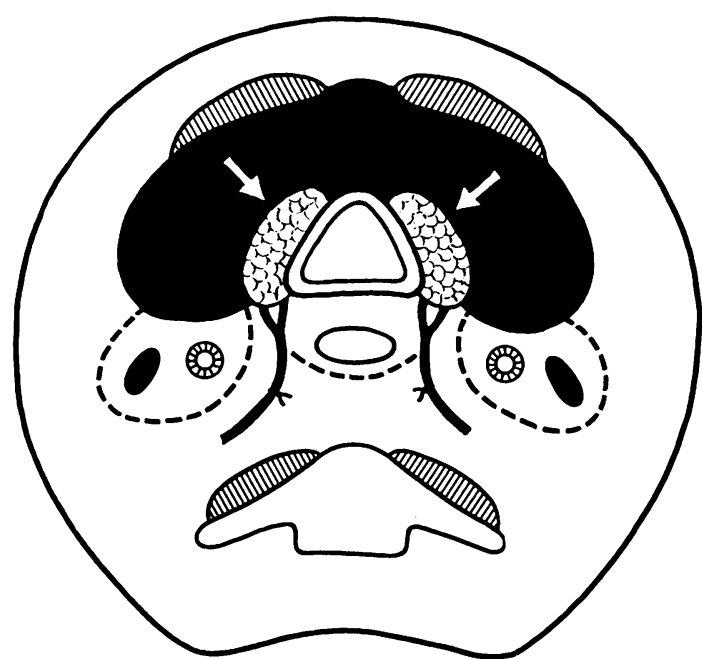

FIG. 25.-A tension haematoma deep to the pretracheal fascia. Removal of skin stitches and Michel clips will not adequately release the pressure on the trachea.

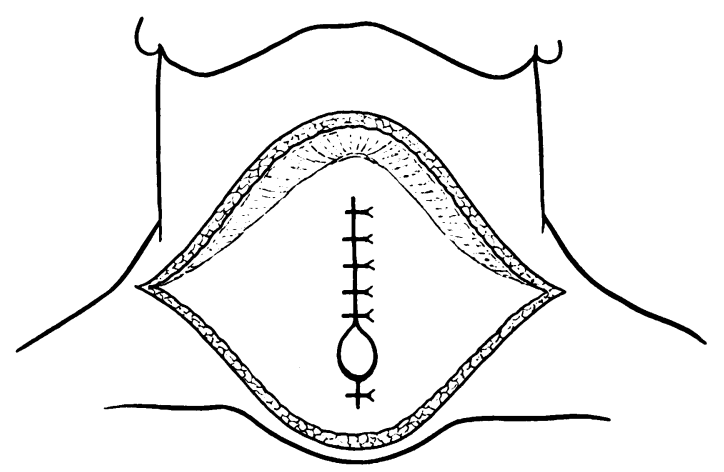

FIG. 26.-An opening is left in the pretracheal fasciainferiorly.

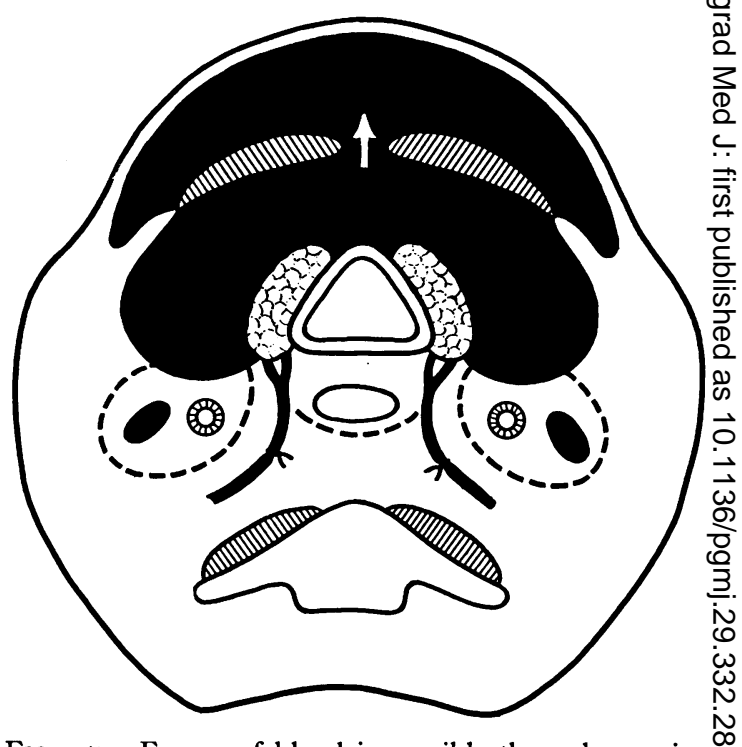

FIG. 27.-Escape of blood is possible through opening in pretracheal fascia into the subcutaneous tissues. 음

들

moved as recurrence of toxicity can occur in this $\vec{c}$ remnant (Figs. 22 and 23 ).

3. Drainage should be of the simplest kind and subcutaneous - with the drainage dam emergifor laterally-at the extremities of the wound-and never from its centre as puckering may follow when the patient swallows. (Fig. 24).

4. The pretracheal fascia should never be com- $\stackrel{\mathbb{Q}}{\square}$ pletely sewn up in the midline or a tension haema- $\overrightarrow{\overrightarrow{0}}$ toma may develop deep to it and cause sudden and 3 severe dyspnoea (Fig. 25). If an opening is deliberately left (Fig. 26) and bleeding from the gland occurs the blood is able to escape sub-흠 cutaneously (Fig. 27).

\section{BIBLIOGRAPHY}

ANSELL, G., and MILLER H. (1952), Lancet, ii, 5. CATTELL, R. B. (1949), 'Transactions of the American Goitre
Association,' p. 201. DONALD, C. (1945), The Postgrad. Med. F., 21, 4I.

FRASER, R., and HARRISON, R. J. (1952), Lancet, 1, 382. NEWSHOLME, G. A. (1952), Lancet, i1, 805. POCHIN, E. E. (1950), Ibid., ii, 84. 